\title{
BMJ Open Development and validation of the Fracture Risk Scale (FRS) that predicts fracture over a 1-year time period in institutionalised frail older people living in Canada: an electronic record- linked longitudinal cohort study
}

\author{
George loannidis, ${ }^{1,2}$ Micaela Jantzi, ${ }^{3}$ Jenn Bucek, ${ }^{3}$ Jonathan D Adachi, ${ }^{1,2}$ \\ Lora Giangregorio, ${ }^{4}$ John Hirdes, ${ }^{3}$ Laura Pickard, ${ }^{1,2}$ Alexandra Papaioannou ${ }^{1,2}$
}

To cite: loannidis G, Jantzi M, Bucek J, et al. Development and validation of the Fracture Risk Scale (FRS) that predicts fracture over a 1-year time period in institutionalised frail older people living in Canada: an electronic record-linked longitudinal cohort study. BMJ Open 2017;7:e016477. doi:10.1136/ bmjopen-2017-016477

- Prepublication history and additional material are published online only. To view please visit the journal online (http://dx.doi. org/10.1136/bmjopen-2017016477).

Received 17 February 2017 Revised 16 June 2017 Accepted 14 July 2017

\section{CrossMark}

${ }^{1}$ Department of Medicine, McMaster University, Hamilton, Ontario, Canada

${ }^{2}$ Geriatric Education and Research in Ageing Sciences Centre, Hamilton, Ontario,

Canada

${ }^{3}$ Department of Health Studies and Gerontology, University of Waterloo, Waterloo, Ontario, Canada

${ }^{4}$ Department of Kinesiology, University of Waterloo, Waterloo, Ontario, Canada

Correspondence to Dr George Ioannidis; g.ioannidis@sympatico.ca

\section{ABSTRACT}

Objectives To develop and validate our Fracture Risk Scale (FRS) over a 1-year time period, using the long-term care (LTC) Resident Assessment Instrument Minimum Data Set Version 2.0 (RAI-MDS 2.0).

Design A retrospective cohort study.

Setting LTC homes in Ontario, Canada.

Participants Older adults who were admitted to LTC and received a RAI-MDS 2.0 admission assessment between 2006 and 2010.

Results A total of 29848 LTC residents were enrolled in the study. Of these 22386 were included in the derivation dataset and 7462 individual were included in the validation dataset. Approximately $2 / 3$ of the entire sample were women and $45 \%$ were 85 years of age or older. A total of $1553(5.2 \%)$ fractures were reported over the 1-year time period. Of these, $959(61.8 \%)$ were hip fractures. Following a hip fracture, $6.3 \%$ of individuals died in the emergency department or as an inpatient admission and did not return to their LTC home. Using decision tree analysis, our final outcome scale had eight risk levels of differentiation. The percentage of individuals with a hip fracture ranged from $0.6 \%$ (lowest risk level) to $12.6 \%$ (highest risk level). The area under the curve of the outcome scale was similar for the derivation (0.67) and validation (0.69) samples, and the scale exhibited a good level of consistency.

Conclusions Our FRS predicts hip fracture over a 1-year time period and should be used as an aid to support clinical decisions in the care planning of LTC residents. Future research should focus on the transformation of our scale to a Clinical Assessment Protocol and to assess the FRS in other healthcare settings.

\section{INTRODUCTION}

Older adults usually enter long-term care (LTC) homes because of difficulties in functional status triggered by physical decline, cognitive impairment or the onset of an acute illness. These individuals are at higher risk for hip fracture due to increased age-related

\section{Strengths and limitations of this study}

- The Fracture Risk Scale (FRS) was developed and validated using a large number of residents living in long-term care (LTC) homes and thus the results may be generalisable to all LTC residents living in Canada.

- The FRS did not use bone mineral density as a predictor of hip fracture, which is difficult to measure in LTC, but used a comprehensive set of community and LTC-specific risk factors to predict new fractures.

- Decision tree analysis was used to develop our outcome scale, which provides an empirically sound, visual representation of the contributing factors for hip fracture among residents living in LTC; and by clinical feedback to improve the instrument's face validity.

- Our study excluded individuals that we believed would not survive the 1-year assessment period. Therefore, our findings may not be generalisable to these residents.

bone loss, ${ }^{1}$ increased propensity to fall ${ }^{2}$ and altered mechanics of the fall, where older individuals are more likely to fall backwards or sideways. ${ }^{34}$ Compared with similarly aged seniors residing in the community, the rate of hip fractures is 1.6 and 2.2 times greater in women and men living in LTC, respectively. ${ }^{5}$ Hip fractures are the most common fracture type in LTC, accounting for $49 \%$ of all fractures. ${ }^{5}$ Furthermore, hip fracture is one of the leading causes of hospitalisation for LTC residents ${ }^{6}$ and is associated with increased mortality, reduced mobility and worsening health-related quality of life. ${ }^{7}$ Approximately $50 \%$ of LTC residents who have some independence in locomotion prior to hip fracture 
either die or develop total dependence within 6 months of their fracture. ${ }^{8}$

Unfortunately, it is difficult to identify LTC residents at high risk for fracture, as the current fracture risk assessment tools in Canada, including the Canadian Fracture Risk Assessment Tool (FRAX) and the Canadian Association of Radiologists and Osteoporosis Canada Tool (CAROC),${ }^{9-12}$ are not valid for or generalisable to LTC. For instance, the instruments provide a 10-year fracture risk assessment timeframe, which is too long, given that $20 \%$ of residents die within 1 year of LTC admission. ${ }^{13}$ In addition, both instruments use bone mineral density as a major factor that predicts future fracture risk. However bone density is challenging to obtain in LTC, and previous work has identified that the use of the FRAX model without bone mineral density identified 98\% of residents as candidates for treatment. ${ }^{14}$ Finally, the instruments do not include potential LTC-specific risk factors (ie, wandering, cognitive impairment and transfer status) for hip fracture which are different than in the community-specific risk factors (ie, age, sex and prior fracture status). ${ }^{15}$ Thus, fracture prediction outputs of FRAX-Canada and CAROC may not be suitable for decision making and care planning among LTC residents who have multiple comorbidities. ${ }^{1617}$

The Resident Assessment Instrument Minimum Data Set Version 2.0 (RAI-MDS 2.0) is a comprehensive, standardised tool that has been implemented in LTC homes in many Canadian provinces. ${ }^{18-20}$ The RAI-MDS 2.0 is used during routine clinical practice and data from the instrument provides an opportunity for healthcare providers to evaluate the healthcare needs and risks of all residents. The instrument is completed within 14 days of a resident entering a home and quarterly thereafter. The RAI-MDS 2.0 includes individual data elements and outcome scores that may provide the necessary information to determine residents at high risk for hip fracture. The purpose of our study was to develop and validate our Fracture Risk Scale (FRS) that predicts hip fracture over a 1-year time period, using RAI-MDS 2.0 data. The ability to screen and identify frail residents at risk for hip fracture is clinically useful for the development of fracture prevention care planning strategies.

\section{METHODS}

\section{Study design}

All admission assessments completed in Ontario LTC homes from 1 April 2006 to 31 March 2010 (n=47556) were selected. Those with multiple admissions were excluded $(\mathrm{n}=4041)$. Among the unique admissions $(n=43515)$ those reported on the RAI-MDS 2.0 to have end-stage disease $(n=511)$, were comatose $(n=12)$, received hospice $(n=16)$ or respite care $(n=785)$, expected a short stay $(n=4016)$ or admission assessment completed more than 14 days after the date of admission $(n=4105)$ were excluded. Those who had no reassessments during the 1-year follow-up $(n=4222)$ were also excluded. The final sample size was 29848 residents. These residents were randomly divided between a derivation $(n=22386)$ and validation sample $(\mathrm{n}=7462)$ for the development and testing of our scale (figure 1). Over the course of a 1-year follow-up period, residents were classified as to the presence or absence of an incident fracture using nationally collected data.

This project continues from previous work done through the Innovations in Data, Evidence and Applications for Persons with Neurological Conditions research project, ${ }^{21}$ and has ethics approval obtained from the University of Waterloo Office of Research Ethics (ORE no 17045).

\section{Incident fractures}

RAI-MDS 2.0 data were linked with the Canadian Discharge Abstract Database (DAD) that captures information regarding each inpatient hospital stay and the National Ambulatory Care Reporting System (NACRS) that captures each emergency department visit. ${ }^{223}$ Linked DAD and NACRS records were available for 2 years prior to the RAI-MDS 2.0 assessment, and at least 1 year after the assessment.

Incident fractures were captured using International Classification of Disease 10 codes. The codes were selected using the Revised Framework for National Surveillance on Osteoporosis and Osteoporosis-related Fractures of the Public Health Agency of Canada. ${ }^{24}$ A resident with at least one of these codes within 1 year after the admission assessment was coded as having a fracture (hip (S72.0, S72.1, S72.2), spine (S22.0, S22.1, S32.0, S32.7, S32.8), humerus (S42.2), forearm (S52.x, S62.x) and pelvis (S32.1, S32.3, S32.4, S32.5, S32.7, S32.8)).

\section{Statistical analyses}

Population characteristics are expressed in count and per cent for categorical variables using SAS V.9.4 (SAS Institute).

A decision tree ${ }^{25}$ was created using the $75 \%$ derivation sample to predict incident hip fractures within 1 year of admission to a LTC home. The unadjusted ORs of over 150 individual items and outcome scales from the RAI-MDS 2.0 were calculated. A clinical expert panel evaluated the relevance of the items, and those that had both face validity and were significantly associated with incident fractures based on the ORs were retained. A recursive partitioning method called $\chi^{2}$ Automatic Interaction Detection was employed ${ }^{25}$ using SAS Enterprise Miner V.13.1 (SAS Institute). The final decision tree was validated in an in-person meeting with clinical experts.

Once the decision tree was completed, the individual nodes were collapsed into eight categories and logistic regression was performed to calculate the odds of having a hip fracture within the first year of admission to an LTC home. c-Statistics were calculated to compare the discriminative properties of the full, derivation and validation samples. 


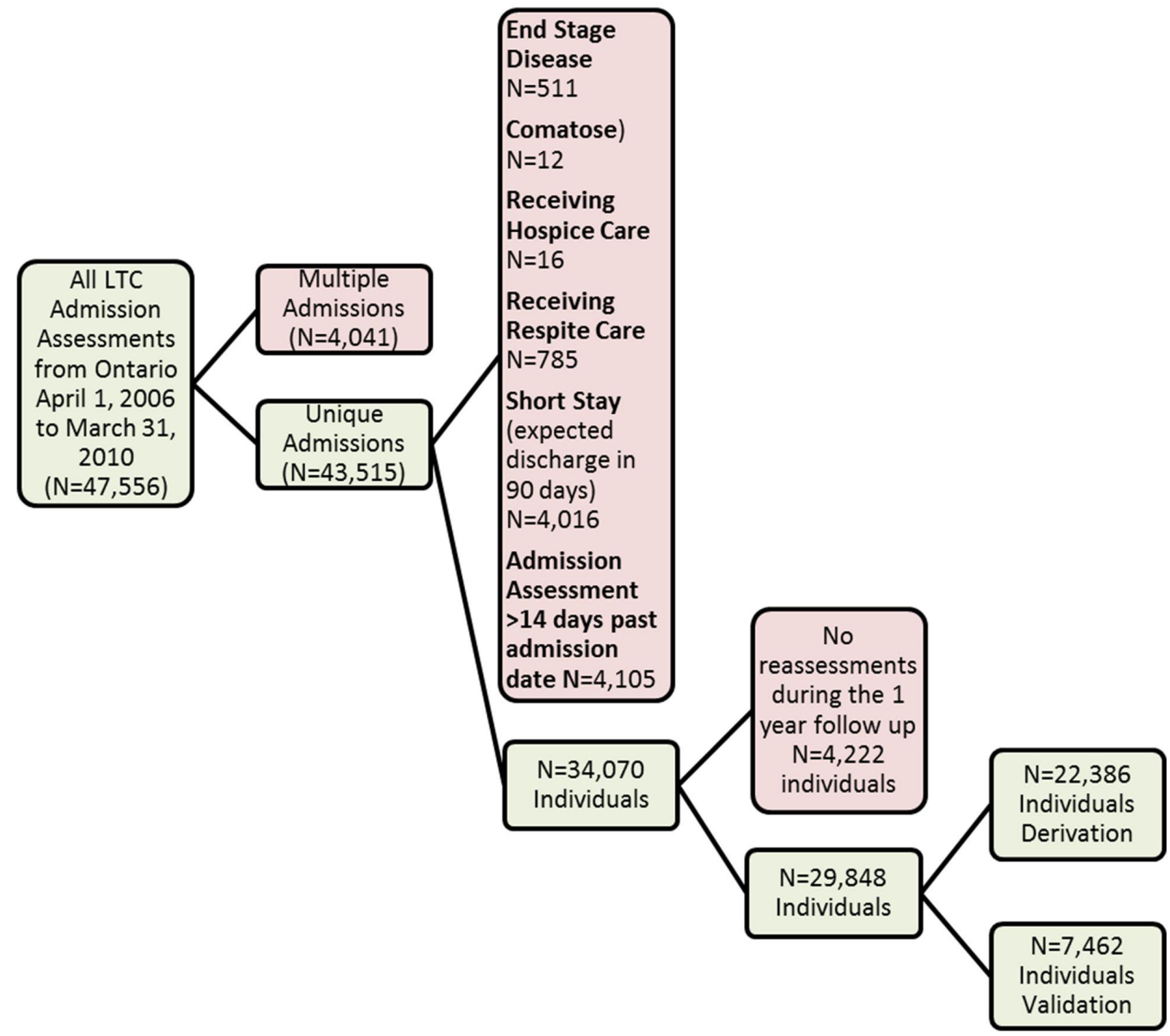

Figure 1 Study sample flow diagram. LTC, long-term care.

\section{RESULTS}

Table 1 displays the population characteristics of residents for the combined, derivation and validation dataset. For the combined sample, approximately $45 \%$ of LTC residents were 85 years and older, $2 / 3$ were women, $1 / 3$ had a prior fall within the past 180 days and $3 \%$ had a prior hip fracture within the past 180 days. A total of 1553 $(5.2 \%)$ new fractures (including hip, spine humerus, forearm and pelvis) were reported over the 1-year time period. Of these, $959(61.8 \%)$ were hip fractures. The fracture proportion was similar for individuals in the derivation and validation samples (data not shown). Only 15 $(0.07 \%)$ older adults had multiple hip fractures over the 1-year time period.

\section{Decision tree model}

The final decision tree model contains 17 leaves. Each leaf represented a distinct proportion of residents with an incident hip fracture during the 1-year assessment period (figure 2). By combining leaves with similar risk, the 17 leaves were collapsed into the FRS, which included eight risk levels of differentiation (figure 3). Our scale's 1-year absolute hip fracture risk levels ranged from $0.6 \%$ to $12.6 \%$ (table 2 ). The ORs show a clear stepped progression of risk, achieving a 23-fold increase in the odds of developing a hip fracture for residents between the lowest to highest risk level (table 3).
Furthermore, the distribution of residents within each risk level decreased as the risk level for hip fracture increased (table 4).

Within our FRS, the ability of an individual to walk in a corridor on the unit (root node) showed the highest discriminatory power, as well as the best ability to organise the tree branches relative to other risk factors. Body mass index and fall status in the past 30 days were risk factors that also had high discriminatory powers. Other variables included in the tool were wandering events, transfer ability (how resident moves between surfaces to and from; bed, chair, wheelchair, standing position), fall status in the past 180 days, prior fracture in past 180 days, cognitive performance and age greater than 85 years (figure 3, online supplementary appendix 1).

\section{Discrimination and predictive accuracy}

The overall discriminative properties of the FRS were similar between the combined ( $c$-statistic $=0.673$ ), derivation (c-statistic $=0.669)$ and validation (c-statistic $=0.687$ ) datasets. In addition, the absolute hip fracture rate for the individual risk levels (table 2), the ORs comparisons (table 3) and the predictive accuracy (figure 2) of the scale were similar between the derivation and validation datasets. Overall, the FRS exhibited a good level of consistency between the datasets. 
Open Access

Table 1 Resident characteristics for the combined, derivation and validation datasets

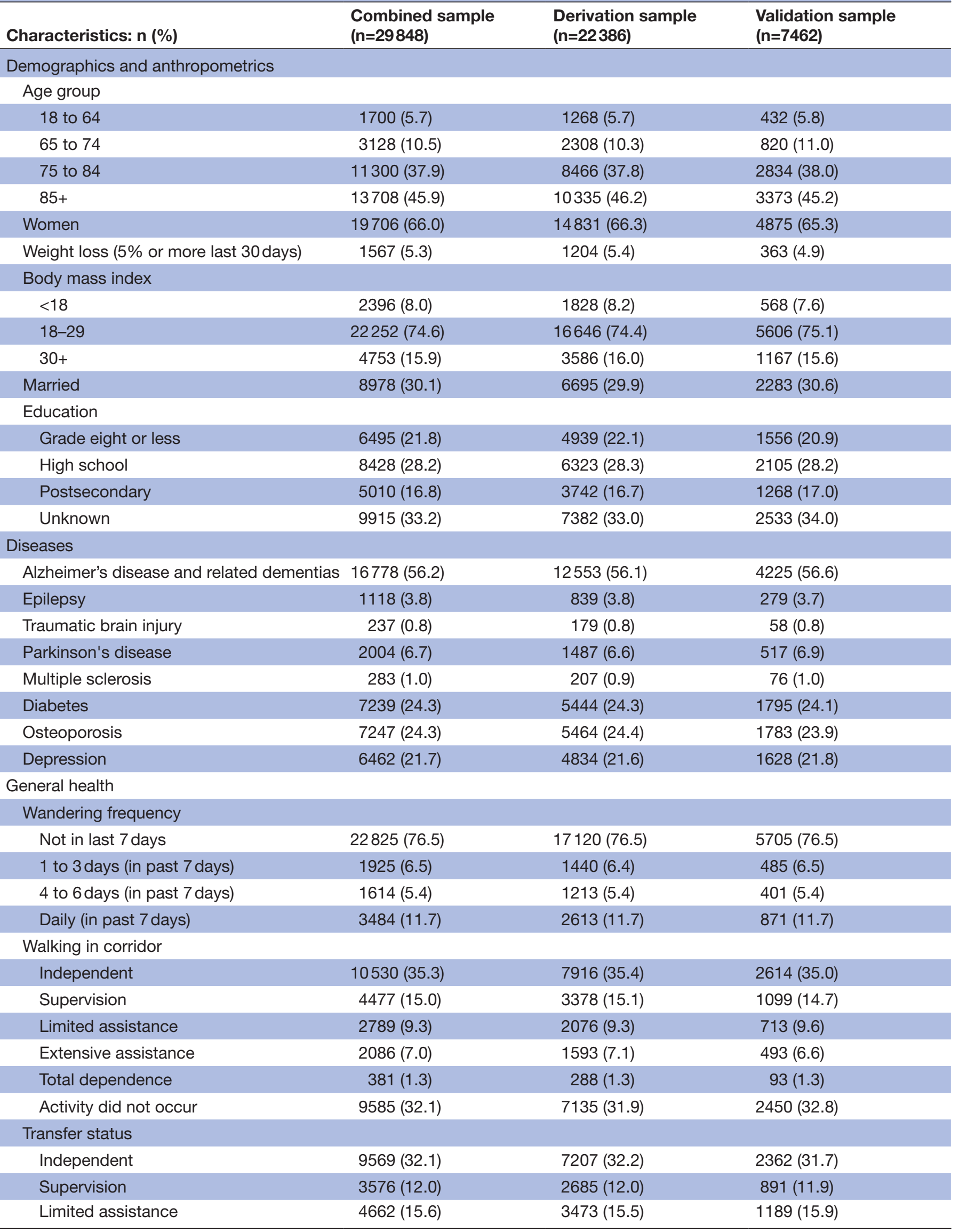




\begin{tabular}{|c|c|c|c|}
\hline Characteristics: n (\%) & $\begin{array}{l}\text { Combined sample } \\
(\mathrm{n}=29848)\end{array}$ & $\begin{array}{l}\text { Derivation sample } \\
(\mathrm{n}=22386)\end{array}$ & $\begin{array}{l}\text { Validation sample } \\
(\mathrm{n}=7462)\end{array}$ \\
\hline Extensive assistance & $7140(23.9)$ & $5364(24.0)$ & $1776(23.8)$ \\
\hline Total dependence & $4806(16.1)$ & $3589(16.0)$ & $1217(16.3)$ \\
\hline Activity did not occur & $95(0.3)$ & $68(0.3)$ & $27(0.4)$ \\
\hline \multicolumn{4}{|l|}{ Cognitive Performance Scale } \\
\hline Intact & $5159(17.3)$ & $3871(17.3)$ & $1288(17.3)$ \\
\hline Borderline intact & $4517(15.1)$ & $3420(15.3)$ & $1097(14.7)$ \\
\hline Mild & $6270(21.0)$ & $4710(21.0)$ & $1560(20.9)$ \\
\hline Moderate & $8697(29.1)$ & $6535(29.2)$ & $2162(29.0)$ \\
\hline Moderately severe & $1650(5.5)$ & $1234(5.5)$ & $416(5.6)$ \\
\hline Severe & $2538(8.5)$ & $1877(8.4)$ & $661(8.9)$ \\
\hline Very severe & $1017(3.4)$ & 739 (3.3) & $278(3.7)$ \\
\hline \multicolumn{4}{|l|}{ Medications (taken last 7 days) } \\
\hline Antipsychotic & $8313(27.9)$ & $6167(27.6)$ & $2146(28.8)$ \\
\hline Antianxiety & $4832(16.2)$ & $3646(16.3)$ & $1186(15.9)$ \\
\hline Antidepressant & $12034(40.3)$ & $9007(40.2)$ & $3027(40.6)$ \\
\hline Hypnotic & $2152(7.2)$ & $1655(7.4)$ & $497(6.7)$ \\
\hline \multicolumn{4}{|l|}{ Medical history } \\
\hline Previous fall in past 30 days & $5228(17.5)$ & $3931(17.6)$ & $1297(17.4)$ \\
\hline Previous fall in past 180 days & $10097(33.8)$ & 7568 (33.8) & $2529(33.9)$ \\
\hline Previous fracture in past 180 days $^{*}$ & $1736(5.8)$ & $1291(5.8)$ & $455(6.0)$ \\
\hline Prior hip fracture in past 180 days & $938(3.1)$ & $692(3.1)$ & $249(3.3)$ \\
\hline
\end{tabular}

*Any hip or other fracture in the past 180 days.

\section{Death rates}

Following a hip fracture, $6.27 \%$ in individuals died in the emergency department or as an inpatient admission and did not return to their LTC facility. The mean length of stay (SD) for those who died during an inpatient admission was 8.9 days $(7.3)$.

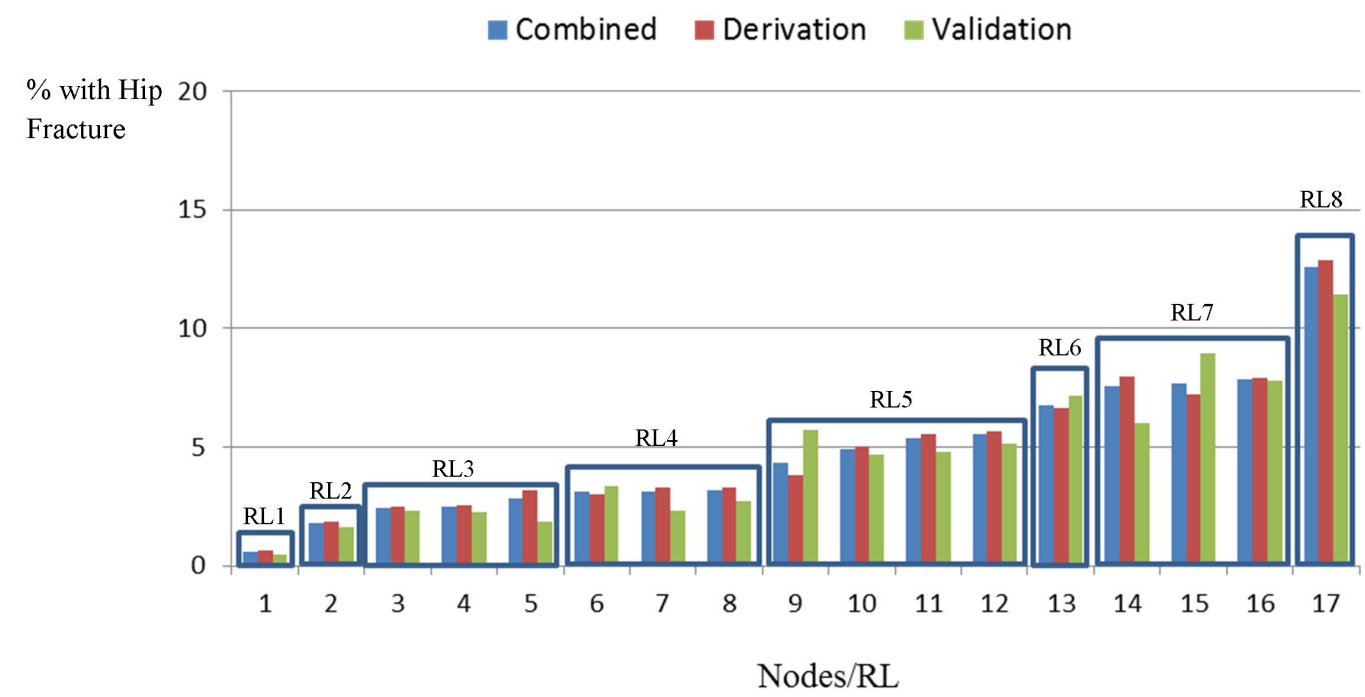

* RL=Risk level derived from decision tree analysis.

Figure 2 Incident hip fracture rates classified by individual decision nodes and the eight hip risk levels for the combined, derivation and validation datasets. 


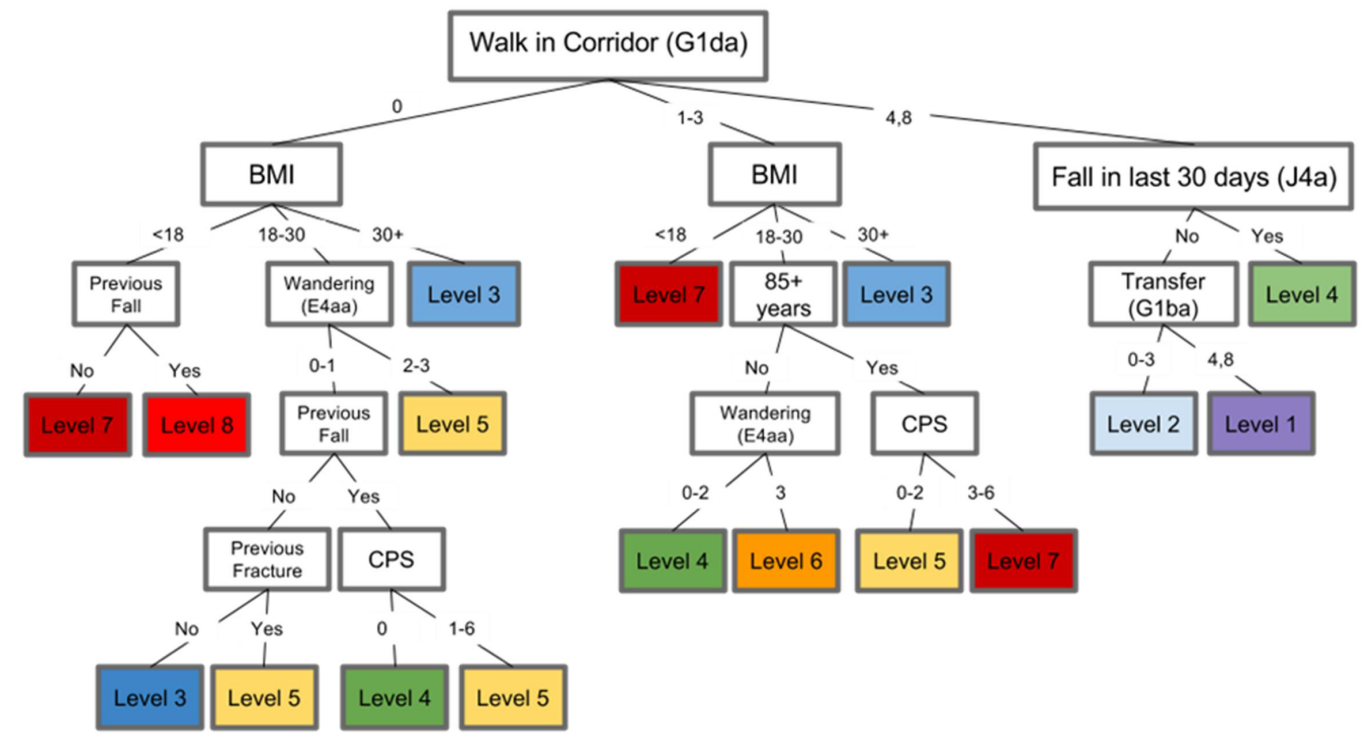

*Previous Fall $=$ Any fall in the past 180 days.

Previous Fracture $=$ Any hip or other fracture in the past 180 days.

Figure 3 Fracture Risk Scale. BMI, body mass index; CPS, Cognitive Performance Scale.

\section{DISCUSSION}

While a large proportion of residents in LTC are at risk of suffering a hip fracture, a fracture care planning gap has been well documented. ${ }^{26-30}$ Potential causes for this planning care gap include inadequate access to bone mineral density testing, a lack of knowledge of clinicians regarding fracture risk assessment and treatment, and the complex nature of providing care to residents in LTC that requires clinical competence. ${ }^{31}$ Therefore, standardised methods must be used to identify residents at risk for hip fracture to reduce the care gap and to improve the efficient allocation and delivery of limited LTC health resources.

Our results show that the FRS is capable of both discriminating and predicting residents at risk for hip fracture over a 1-year time period. Our findings indicate that in addition to community risk factors for hip fracture that are used in the FRAX and CAROC instruments, there are several LTC-specific risk factors that are important in predicting hip fracture risk including walking ability, wandering, falling, cognitive impairment and transfer status. Our scale identifies eight risk levels for hip fracture in LTC and provides the clinical information that is needed to develop person-centred care plans. Of note, the distribution property of the scale allocates over $50 \%$ of the assessed residents into the lowest three risk levels with progressively fewer residents spread across each of the higher risk levels. The scale's properties are beneficial for the potential transformation of the FRS to a Clinical Assessment Protocol (CAP).

Our intention is to further develop the FRS into a CAP algorithm, to assist LTC health professionals to systematically interpret fracture risk levels that are generated by the instrument and to inform clinical decision-making as part of the care planning process. The CAP may combine our scale's eight risk levels into three risk categories for hip fracture (ie, very high risk, high risk and lower risk for

\begin{tabular}{lccc}
\hline Table 2 & Incident hip fracture rates by hip fracture risk levels for the combined, derivation and validation datasets \\
\hline $\begin{array}{l}\text { Hip fracture risk levels } \\
\text { categories }\end{array}$ & $\begin{array}{l}\text { Combined sample per cent } \\
\text { with hip fracture }\end{array}$ & $\begin{array}{l}\text { Derivation sample per cent } \\
\text { with hip fracture }\end{array}$ & $\begin{array}{l}\text { Validation sample per cent } \\
\text { with hip fracture }\end{array}$ \\
\hline Hip fracture risk level 1 & 0.6 & 0.67 & 0.5 \\
\hline Hip fracture risk level 2 & 1.8 & 1.88 & 1.64 \\
Hip fracture risk level 3 & 2.5 & 2.64 & 2.24 \\
Hip fracture risk level 4 & 3.1 & 3.2 & 2.96 \\
Hip fracture risk level 5 & 5 & 4.9 & 5.1 \\
Hip fracture risk level 6 & 6.8 & 6.64 & 7.14 \\
Hip fracture risk level 7 & 7.8 & 7.8 & 7.68 \\
Hip fracture risk level 8 & 12.6 & 12.9 & 11.43 \\
\hline
\end{tabular}


Table 3 ORs comparisons for the eight hip fracture risk levels for full, derivation and validation datasets

\begin{tabular}{|c|c|c|c|}
\hline Hip fracture risk level categories & $\begin{array}{l}\text { Combined sample } \\
\text { ORs } \\
\text { (95\% Cl) }\end{array}$ & $\begin{array}{l}\text { Derivation sample } \\
\text { ORs } \\
(95 \% \mathrm{Cl})\end{array}$ & $\begin{array}{l}\text { Validation sample } \\
\text { ORs } \\
\text { (95\% Cl) }\end{array}$ \\
\hline Hip fracture risk level 2 vs 1 & 3.0 (1.9 to 4.6$)$ & $2.9(1.7$ to 4.7$)$ & $3.3(1.3$ to 8.9$)$ \\
\hline Hip fracture risk level 3 vs 1 & 4.2 (2.7 to 6.3$)$ & 4.1 (2.5 to 6.5$)$ & $4.6(1.8$ to 11.7$)$ \\
\hline Hip fracture risk level 4 vs 1 & $5.2(3.4$ to 7.9$)$ & 4.9 (3.1 to 7.9$)$ & 6.1 (2.4 to 15.6$)$ \\
\hline Hip fracture risk level 5 vs 1 & $8.3(5.5$ to 12.6$)$ & 7.7 (4.8 to 12.2$)$ & 10.8 (4.3 to 26.9$)$ \\
\hline Hip fracture risk level 6 vs 1 & $11.6(7.0$ to 19.1$)$ & $10.6(6.0$ to 18.7$)$ & 15.4 (5.3 to 45$)$ \\
\hline Hip fracture risk level 7 vs 1 & $13.4(8.8$ to 20.5$)$ & 12.6 (7.9 to 20.2$)$ & 16.7 (6.6 to 42.2$)$ \\
\hline Hip fracture risk level 8 vs 1 & 23.0 (12.5 to 42.3$)$ & 22.1 (11.2 to 43.9$)$ & $25.9(6.6$ to 101$)$ \\
\hline
\end{tabular}

hip fracture). The very high-risk category may be defined as risk levels 7 and 8; high risk as risk levels 4, 5 and 6 and lower risk as risk levels 1, 2 and 3. The proposed three-level triggering CAP is similar to CAPs used in other interRAI instruments. ${ }^{32-34}$ The CAP may be triggered for the very high risk and the high risk categories, which represents $8.5 \%$ and $35.7 \%$ of the resident population in LTC, respectively. The non-triggered lower-risk category represents $55.8 \%$ of the population. This large population of low-risk persons within the potential CAP is important because the triggering of too many high risk individuals may quickly overwhelm LTC resources that are needed for clinical management and may fail to differentiate individuals at the point of care. Person-centred care planning recommendations for those that trigger the CAP may be based on effective interventions recommended by LTC guidelines from Canada and around the world, and include vitamin $\mathrm{D}$ and calcium supplementation, hip protectors, exercise, multifactorial interventions to prevent falls and pharmacological therapies. ${ }^{35-37}$ The CAP outputs will assist in resident care planning and the process should reduce the risk of hip fracture, increase life expectancy, preserve or improve quality of life and reduce healthcare costs.

Our findings should be interpreted based on the strengths and limitations of our study design. Strengths that may prevent bias include the large number of residents that were used to develop and validate our outcome scale. A comprehensive set of independent variables were included in the analyses. Our outcome scale did not use bone mineral density as a predictor of hip fracture, which is difficult to measure in LTC. We used a 'gold standard' method (DAD/NACRS databases) to assess incident hip fracture status. Decision tree analysis was used to develop our outcome scale, which provides an empirically sound, visual representation of the contributing factors for hip fracture among residents living in LTC; and by clinical feedback to improve the instrument's face validity. Using decision tree analysis may have higher utility in identifying high risk individuals relative to traditional algorithm developed in LTC using regression analyses ${ }^{38} 39$ because of the no parametric assumptions of the technique, the method's distinctive clustering of risk factors and the tree's ability to better account for independent and dependent variable outliers. Furthermore, the FRS will be a standardised tool that uses existing items from the RAI-MDS 2.0, will automatically generate fracture risk assessments for residents as part of the RAI-MDS 2.0 quarterly data collection process and will rely on existing assessor training skills and resources that are currently present in LTC homes. The use of our scale will minimise the duplication of work that is often required to support non-integrated tools, such as FRAX, CAROC or QFracture. $^{9-1240}$ Our instrument has a logical flow, and is easily interpretable by LTC healthcare professionals. As a product of the process by which the scale was created,

Table 4 Distribution of residents by hip fracture risk level for combined, derivation and validation datasets

\begin{tabular}{lllr}
\hline Hip fracture risk level categories & $\begin{array}{l}\text { Combined sample: } \\
\%(\mathbf{n}) \text { in each level }\end{array}$ & $\begin{array}{l}\text { Derivation sample: } \\
\%(\mathbf{n}) \text { in each level }\end{array}$ & $\begin{array}{l}\text { Validation sample: } \\
\%(\mathbf{n}) \text { in each level }\end{array}$ \\
\hline Hip fracture risk level 1 & $13.5(4014)$ & $13.4(3007)$ & $13.5(1007)$ \\
\hline Hip fracture risk level 2 & $18.3(5446)$ & $18.3(4104)$ & $24.5(1827)$ \\
Hip fracture risk level 3 & $24.1(7198)$ & $24(5371)$ & $17.2(1282)$ \\
Hip fracture risk level 4 & $17.0(5065)$ & $16.9(3783)$ & $16.3(1216)$ \\
Hip fracture risk level 5 & $16.6(4948)$ & $16.7(3732)$ & $2.1(154)$ \\
Hip fracture risk level 6 & $2.1(636)$ & $2.2(482)$ & $8.0(599)$ \\
Hip fracture risk level 7 & $8.0(2382)$ & $8.0(1783)$ & $0.5(35)$ \\
\hline Hip fracture risk level 8 & $0.5(159)$ & $0.6(124)$ & \\
\hline
\end{tabular}


we believe that our scale's approval and use in LTC will be enhanced. Finally, our FRS uses similar items that are collected using the next version of the instrument (interRAI LTC Facilities) that is used internationally and in some Canadian provinces, ${ }^{20}$ and by the MDS-Home Care instrument ${ }^{41}$ and thus, our tool may potentially be useful globally and in home care settings.

Our study limitations include the exclusion of individuals that we believed would not survive the 1-year assessment period. Therefore, our findings may not be generalisable to these residents. The study was limited to the independent variables available in the RAI-MDS 2.0 and may not have captured all relevant risk factors for hip fractures among LTC residents. Finally, it is not clear if our results are unique to LTC residents and further validation studies will be needed in different populations (ie, home care).

In conclusion, the findings of our study provide support for the discriminatory and predictive properties of the FRS. The instrument may have implications for health strategy, service delivery and care planning that may impact policy choices for vulnerable residents living in LTC. Our scale that predicts hip fracture over a 1-year time period may be used as an aid to support clinical decisions in the care planning process and may be incorporated as part of a comprehensive clinical assessment where the preference of the resident should be considered. Future research should focus on comparing the FRS to other fracture prediction instruments, developing a CAP for the scale and evaluating the performance of the FRS in home care.

Contributors Contributions: Gl was responsible for study design, data analysis interpretation and drafting of manuscript, MJ was responsible for study design, data analysis and interpretation and drafting of manuscript. JB, JDA, LG, JH, LP and AP were responsible for study design, data interpretation and critical review of the manuscript. All authors read and approved the final manuscript.

Funding The Ministry of Health and Long-Term care through the Ontario Osteoporosis Strategy for Long-Term Care.

Disclaimer The funding sources had no role in the design and conduct of the study; collection, management, analysis and interpretation of the data; or preparation, review or approval of the manuscript.

Competing interests All authors have completed the ICMJE uniform disclosure form at www.icmje.org/coi_disclosure.pdf and declare: no support from any organisation for the submitted work; no financial relationships with any organisations that might have an interest in the submitted work in the previous three years; no other relationships or activities that could appear to have influenced the submitted work (Gl, MJ, JB, JH). LG reports personal fees from ICON. AP and LP report grants from Ontario Ministry of Health and Long-Term Care Ontario Osteoporosis Strategy. JDA reports grants and personal fees from Amgen, grants and personal fees from Eli Lilly, personal fees from AgNovos, during the conduct of the study; non-financial support from Osteoporosis Canada, non-financial support from International Osteoporosis Foundation, outside the submitted work.

Ethics approval Obtained from the University of Waterloo Office of Research Ethics (ORE no 17045).

Provenance and peer review Not commissioned; externally peer reviewed.

Data sharing statement № additional data are available.

Open Access This is an Open Access article distributed in accordance with the Creative Commons Attribution Non Commercial (CC BY-NC 4.0) license, which permits others to distribute, remix, adapt, build upon this work non-commercially, and license their derivative works on different terms, provided the original work is properly cited and the use is non-commercial. See: http://creativecommons.org/ licenses/by-nc/4.0/

(C) Article author(s) (or their employer(s) unless otherwise stated in the text of the article) 2017. All rights reserved. No commercial use is permitted unless otherwise expressly granted.

\section{REFERENCES}

1. Choi YJ. Dual-Energy X-Ray Absorptiometry: Beyond Bone Mineral Density Determination. Endocrinol Metab 2016;31:25-30.

2. Morris JN, Howard EP, Steel K, et al. Strategies to reduce the risk of falling: Cohort study analysis with 1-year follow-up in community dwelling older adults. BMC Geriatr 2016;16:92.

3. Nevitt MC, Cummings SR. Type of fall and risk of hip and wrist fractures: the study of osteoporotic fractures. The Study of Osteoporotic Fractures Research Group. J Am Geriatr Soc 1993;41:1226-34.

4. Talbot LA, Musiol RJ, Witham EK, et al. Falls in young, middleaged and older community dwelling adults: perceived cause, environmental factors and injury. BMC Public Health 2005;5:86.

5. Papaioannou A, Kennedy CC, loannidis G, et al. Comparative trends in incident fracture rates for all long-term care and communitydwelling seniors in Ontario, Canada, 2002-2012. Osteoporos Int 2016;27:887-97.

6. Ronald LA, McGregor MJ, McGrail KM, et al. Hospitalization rates of nursing home residents and community-dwelling seniors in British Columbia. Can J Aging 2008;27:109-15.

7. Dyer SM, Crotty M, Fairhall N, et al. A critical review of the long-term disability outcomes following hip fracture. BMC Geriatr 2016;16:158.

8. Neuman MD, Silber JH, Magaziner JS, et al. Survival and functional outcomes after hip fracture among nursing home residents. JAMA Intern Med 2014;174:1273-80.

9. Siminoski K, Leslie WD, Frame $\mathrm{H}$, et al. Recommendations for bone mineral density reporting in Canada: a shift to absolute fracture risk assessment. J Clin Densitom 2007;10:120-3.

10. Siminoski K, Leslie WD, Frame $\mathrm{H}$, et al. Recommendations for bone mineral density reporting in Canada. Can Assoc Radiol J 2005;56:178-88.

11. Kanis JA, Johnell $O$, De Laet $C$, et al. A meta-analysis of previous fracture and subsequent fracture risk. Bone 2004;35:375-82.

12. Leslie WD, Lix LM, Langsetmo $L$, et al. Construction of a FRAX® model for the assessment of fracture probability in Canada and implications for treatment. Osteoporos Int 2011;22:817-27.

13. Bravo G, Dubois MF, De Wals $P$, et al. Relationship between regulatory status, quality of care, and three-year mortality in Canadian residential care facilities: a longitudinal study. Health Serv Res 2002;37:1181-96.

14. Greenspan SL, Perera S, Nace D, et al. FRAX or fiction: determining optimal screening strategies for treatment of osteoporosis in residents in long-term care facilities. J Am Geriatr Soc 2012;60:684-90.

15. Khatib R, Santesso N, Pickard L, et al. Fracture risk in long term care: a systematic review and meta-analysis of prospective observational studies. BMC Geriatr 2014;14:130.

16. Cox L, Kloseck M, Crilly R, et al. Underrepresentation of individuals 80 years of age and older in chronic disease clinical practice guidelines. Can Fam Physician 2011;57:e263-9.

17. Mutasingwa DR, Ge H, Upshur RE. How applicable are clinical practice guidelines to elderly patients with comorbidities? Can Fam Physician 2011;57:e253-62.

18. Morris JN, Nonemaker S, Murphy K, et al. A commitment to change: revision of HCFA's RAI. J Am Geriatr Soc 1997;45:1011-6.

19. Hawes C, Morris JN, Phillips CD, et al. Development of the nursing home Resident Assessment Instrument in the USA. Age Ageing 1997;26(Suppl 2):19-25.

20. Hirdes JP, Ljunggren G, Morris JN, et al. Reliability of the interRAI suite of assessment instruments: a 12-country study of an integrated health information system. BMC Health Serv Res 2008;8:277.

21. Jantzi M, Maher AC, loannidis $G$, et al. Individuals with neurological diseases are at increased risk of fractures within 180 days of admission to long-term care in Ontario. Age Ageing 2015;44:252-7.

22. Canadian Institute for Health Information. Data Quality Documentation, Discharge Abstract Database - Multi-Year Information. Ottawa, ON: CIHI, 2012. https://www.cihi.ca/sites/ default/files/document/nacrs_multi-year_info_en.pdf (accessed 20 Dec 2016)

23. Canadian Institute for Health Information. Data Quality Documentation National Ambulatory Care Reporting System - MultiYear Information. Ottawa: CIHI, 2012. 
24. O'Donnell S. Canadian Chronic Disease Surveillance System Osteoporosis Working G. Use of administrative data for national surveillance of osteoporosis and related fractures in Canada: results from a feasibility study. Arch Osteoporos 2013;8:143.

25. Kass GV. An Exploratory Technique for Investigating Large Quantities of Categorical Data. App/ Stat 1980;29:119.

26. Kennedy CC, loannidis G, Thabane L, et al. Osteoporosis prescribing in long-term care: impact of a provincial knowledge translation strategy. Can J Aging 2015;34:137-48.

27. Jachna CM, Shireman TI, Whittle J, et al. Differing patterns of antiresorptive pharmacotherapy in nursing facility residents and community dwellers. J Am Geriatr Soc 2005;53:1275-81.

28. Kennedy CC, loannidis G, Thabane L, et al. Successful knowledge translation intervention in long-term care: final results from the vitamin D and osteoporosis study (ViDOS) pilot cluster randomized controlled trial. Trials 2015;16:214.

29. Colón-Emeric CS, Lyles KW, House P, et al. Randomized trial to improve fracture prevention in nursing home residents. Am J Med 2007;120:886-92.

30. Giangregorio LM, Jantzi M, Papaioannou A, et al. Osteoporosis management among residents living in long-term care. Osteoporos Int 2009;20:1471-8.

31. Wall $M$, Lohfeld $L$, Giangregorio $L$, et al. Fracture risk assessment in long-term care: a survey of long-term care physicians. BMC Geriatr 2013;13:109.

32. Perlman CM, Hirdes JP, Vigod S. Psychiatric Rehospitalization: Development of a Person-Level Indicator for Care Planning and Quality Assurance. Prim Care Companion CNS Disord 2015;17.

33. Neufeld E, Perlman CM, Hirdes JP. Predicting inpatient aggression using the InterRAl risk of harm to others clinical assessment protocol: a tool for risk assessment and care planning. $J$ Behav Health Serv Res 2012;39:472-80.

34. Mathias K, Hirdes JP, Pittman D. A care planning strategy for traumatic life events in community mental health and inpatient psychiatry based on the InterRAl assessment instruments. Community Ment Health J 2010;46:621-7.

35. Papaioannou A, Santesso N, Morin SN, et al. Recommendations for preventing fracture in long-term care. CMAJ 2015;187:1135-44.

36. Duque G, Close JJ, de Jager JP, et al. Treatment for osteoporosis in Australian residential aged care facilities: consensus recommendations for fracture prevention. Med J Aust 2010;193:173-9.

37. Duque G, Lord SR, Mak J, et al. Treatment of Osteoporosis in Australian Residential Aged Care Facilities: Update on Consensus Recommendations for Fracture Prevention. J Am Med Dir Assoc 2016;17:852-9.

38. Colón-Emeric CS, Biggs DP, Schenck AP, et al. Risk factors for hip fracture in skilled nursing facilities: who should be evaluated? Osteoporos Int 2003;14:484-9.

39. Chen JS, Sambrook PN, Simpson JM, et al. A selection strategy was developed for fracture reduction programs in frail older people. $J$ Clin Epidemiol 2010;63:679-85.

40. Hippisley-Cox J, Coupland C. Predicting risk of osteoporotic fracture in men and women in England and Wales: prospective derivation and validation of QFractureScores. BMJ 2009:339:b4229.

41. Morris JN, Fries BE, Steel K, et al. Comprehensive clinical assessment in community setting: applicability of the MDS-HC. J Am Geriatr Soc 1997;45:1017-24. 